\title{
Preoperative plasma glucose level
}

\author{
J. J. MORRICE, K. M. TAYLOR, J. I. BLAIR, and D. G. YOUNG \\ From the Department of Paediatric Surgery, Royal Hospital for Sick Children, Glasgow
}

\begin{abstract}
Morrice, J. J., Taylor, K. M., Blair, J. I., and Young, D. G. (1974). Archives of Disease in Childhood, 49, 898. Preoperative plasma glucose level. The plasma glucose level of 25 infants and children who had routine preparation for anaesthesia and operation has been measured immediately after induction of anaesthesia. The mean plasma glucose level was $66 \mathrm{mg} / 100 \mathrm{ml}$. 5 patients had plasma glucose of 40 $\mathrm{mg} / 100 \mathrm{ml}$ or less. In a similar group in respect of age and weight a milk feed was given 4 hours before operation. The mean plasma glucose in the 20 patients in this group was $82 \mathrm{mg} / 100 \mathrm{ml}$ and no patient had a plasma glucose of less than $60 \mathrm{mg} / 100$ $\mathrm{ml}$. No problems were encountered by giving the milk feed 4 hours before operation.
\end{abstract}

To minimize the danger of vomiting and inhalation of vomit during induction or on recovery from general anaesthesia it is routine practice to ensure that the patient is presented for anaesthesia after a fast of at least 4 hours. The dangers of vomiting have been stressed so much that in most hospitals patients coming for anaesthesia have been starved for periods considerably in excess of 4 hours. This study was undertaken to determine the blood glucose levels in patients treated in the standard fashion of preoperative fasting and to compare this with a similar group of infants who had been given an oral milk feed 4 hours before operation.

\section{Patients and methods}

Patients under 5 years of age who were admitted for relatively minor surgical procedures were studied. They were arbitrarily split into 2 groups. 25 patients

Received 24 April 1974. (group A) were treated in the routine manner. On investigating the duration of the preoperative period of fasting in these patients it was found to vary from 6 hours to 12 hours and on one occasion was over 12 hours. 20 infants (group B) were prepared in the routine fashion but 4 hours before operation each was given a milk feed of $10 \mathrm{ml} / \mathrm{kg}$ up to a maximum of $300 \mathrm{ml}$. (This upper limit was agreed before starting the series, but none of the patients weighed enough to require this volume.) The basic information on the 2 groups is given in Table I. The mean age of group A was 21.4 months compared with $17 \cdot 2$ months in group $B$, and the mean weight $10.77 \mathrm{~kg}$ and $10 \cdot 72 \mathrm{~kg}$, respectively. These differences are not statistically significant.

Premedication was given as ordered by the anaesthetist and the patients taken to theatre. Anaesthesia was induced by inhalation of nitrous oxide, oxygen, and halothane. Whenever the patients were anaesthetized a capillary blood sample was taken by a finger or heel prick. All patients had a good peripheral circulation at the time the blood sample was taken. The plasma glucose level was measured using the glucose oxidase autoanalyser method (Morley, Dawson, and Marks, 1968).

\section{TABLE I}

Age and weight and plasma glucose levels of patients in whom preoperative plasma glucose levels were studied: group $A$ had standard preoperative care and group $B$ were given milk 4 hours before operation

\begin{tabular}{l|c|c}
\hline & Group A & Group B \\
\hline No. of patients & 25 & 20 \\
Mean age (and range) & $21 \cdot 4 \mathrm{mth}(3 \mathrm{dy}-59 \mathrm{mth})$ & $17 \cdot 2 \mathrm{mth}(3-42 \mathrm{mth})$ \\
Mean weight (and range) $(\mathrm{kg})$ & $10 \cdot 77(3 \cdot 23-18 \cdot 2)$ & $10 \cdot 72(5 \cdot 8-20 \cdot 0)$ \\
Mean true glucose $\pm \mathrm{SEM}$ (and range) & $66 \cdot 1^{\star} \pm 3 \cdot 7(29-98)$ & $82 \cdot 1 \star \pm 3 \cdot 4(62-120)$ \\
(mg/100 ml) & & \\
\hline
\end{tabular}

${ }^{\star} \mathrm{P}<0.001$ for difference in mean true glucose level between the 2 groups. 


\section{Results}

The plasma glucose levels for group A and group $B$ are given in Table $I$, and the distributions are shown in the Fig. The mean plasma glucose in group A was $66.1 \mathrm{mg} / 100 \mathrm{ml}$, and in group B the mean was $82.1 \mathrm{mg} / 100 \mathrm{ml}$, a significant difference $(P<0.001)$. In group $A 7$ patients had a plasma glucose of less than $60 \mathrm{mg} / 100 \mathrm{ml}$, while none in group B had a level as low as this. $56 \%$ of group A had a glucose level below $70 \mathrm{mg} / 100 \mathrm{ml}$ compared with $25 \%$ in group B. 5 patients in the survey had a plasma glucose level of $40 \mathrm{mg} / 100 \mathrm{ml}$ or less. We examined whether this was a group of patients who should clinically have been identified as a special category or if they had been fasting for an excessively long period of time (Table II). As far as age, weight, and duration of fasting were concerned, they do not differ from the remainder of the control group.

None of the patients in either group showed overt signs or symptoms of hypoglycaemia. There were no problems related to the induction of anaesthesia in either group nor were untoward signs or symptoms noted in the postanaesthetic phase.

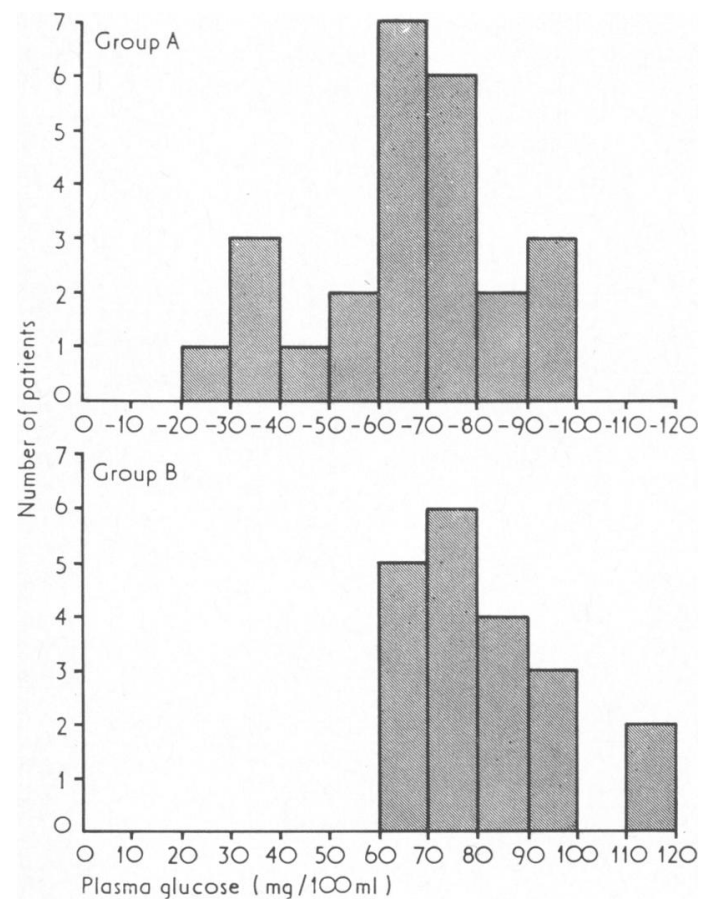

FIG.-Distribution of preoperative plasma glucose levels in group $A$ patients (standard preoperative care) and group $B$ (given milk 4 hours before operation).
TABLE II

Details of the hypoglycaemic patients

Hypoglycaemic group (no. $=5$ )

\begin{tabular}{l|c}
\hline True plasma glucose $(\mathrm{mg} / 100 \mathrm{ml})$ & $29,30,33,40,40$ \\
Fasting time (hr) & $7 \cdot 5,10,7 \cdot 5,8 \cdot 5$ \\
Age (mth) & $4-59$ \\
Mean age (mths) & $19 \cdot 8$ \\
Weight (kg) & $6 \cdot 0-16 \cdot 6$ \\
Mean weight (kg) & $10 \cdot 23$ \\
\hline
\end{tabular}

\section{Discussion}

The level of glucose in the plasma or blood necessary to maintain normal cellular metabolism in the adult or child is not known with certainty. This has been obvious from the difficulty which there has been in defining the plasma glucose level at which hypoglycaemia exists, and many different levels from $40-70 \mathrm{mg} / 100 \mathrm{ml}$ have been quoted (Ehrlich, 1971; Pagliara et al., 1973).

In the present survey of patients, group A undergoing standard preoperative fasting before anaesthesia and operation were always found to have a longer preoperative period of starvation than was intended. This was usually 6-8 hours, but in some was longer and on one occasion exceeded 12 hours. The mean plasma glucose for the 25 patients in this group was $66 \cdot 1 \mathrm{mg} / 100 \mathrm{ml}$ and 5 of these children were found to have a true plasma glucose of $\mathbf{4 0}$ $\mathrm{mg} / 100 \mathrm{ml}$ or less. The low levels occurred in children with a moderate period of starvation and did not simply occur in patients with a very prolonged preoperative fast. That these levels are very low is clear, but what is not clear is whether this hypoglycaemia is of sufficient degree tc be potentially dangerous. The patients with these low levels did not show any clinical signs suggestive of hypoglycaemia but it seems undesirable that patients about to be subjected to the added stress of an anaesthetic and operation should come in such a physiological state. During operation there is a rise in the plasma glucose level in the normal adult but it has been shown that children do not respond with a hyperglycaemic reaction to the same degree (Watson, 1972; Clarke, 1970).

A milk feed given 4 hours before operation to a comparable group of children resulted in all patients having a plasma glucose above $60 \mathrm{mg} / 100 \mathrm{ml}$. The maintenance of the plasma glucose within these more physiological levels seems desirable at least until more information is available on what the essential glucose levels are for a child about to be subjected to the stress of an operation. Similar results have been reported from a study in Newcastle 
TABLE III

Comparison of Newcastle and Glasgow studies on preoperative plasma glucose levels

\begin{tabular}{c|l|c}
\hline $\begin{array}{c}\text { Glucose level } \\
(\mathrm{mg} / 100 \mathrm{ml})\end{array}$ & \multicolumn{1}{|c|}{ Routine care } & $\begin{array}{c}\text { Fed 4 hr } \\
\text { before operation }\end{array}$ \\
\hline$>60$ & $\begin{array}{l}\text { Bevan and Burn }(19 ; 3) \\
\text { Present series 28\% }\end{array}$ & $\begin{array}{r}13 \% \\
0 \%\end{array}$ \\
$>70$ & Bevan and Burn (1973) 59\% & $33 \%$ \\
& Present series 56\% & $25 \%$ \\
\hline
\end{tabular}

(Bevan and Burn, 1973), and the results of that study are compared with the present study (Table III).

The danger of giving a feed 4 hours before operation is primarily that the patient may retain the milk in the stomach and then vomit either during induction of anaesthesia or in the recovery phase. Inhalation of gastric contents is a known potential danger. In the present series no such problems were encountered and the children who did have a nasogastric tube passed did not have a significant gastric residue. In emergency surgery the accepted practice which evolved through experience has been to accept a 4 hour preoperative fast. In these emergency situations there are often additional factors which will contribute to delay in gastric emptying. In the patient for elective operation it therefore seems desirable that the organization of hospital practice should be revised so that patients do receive a milk feed 4-6 hours before induction of anaesthesia. It is undesirable for infants and children to be starved for periods in excess of this time. Hypoglycaemia then becomes a potential hazard.

We wish to thank the nursing staff and Drs. C. S. Cairns, J. Collins, D. A. Miller, and J. Munro of the Royal Hospital for Sick Children, Glasgow, for help and co-operation in performing this study.

\section{REFERENCES}

Bevan, J. C., and Burn, M. C. (1973). Acid base changes and anaesthesia. The influence of pre-operative starvation and feeding in paediatric surgical patients. Anaesthesia, 28, 415.

Clarke, R. S. J. (1970). The hyperglycaemic response to different types of surgery and anaesthesia. British fournal of Anaesthesia, 42, 45.

Ehrlich, R. M. (1971). Hypoglycaemia in infancy and childhood. Archives of Disease in Childhood, 46, 716.

Morley, G., Dawson, A., and Marks, V. (1968). Manual and autoanalyser methods for measuring blood glucose using guaiacum and glucose oxidase. Proceedings of the Association of Clinical Biochemists, 5, 42.

Pagliara, A. S., Karl, I. E., Haymond, M., and Kipnis, D. M. (1973). Hypoglycaemia in infancy and childhood. Fournal of Pediatrics, 82, 365.

Watson, B. G. (1972). Blood glucose levels in children during surgery. British fournal of Anaesthesia, 44, 712.

Correspondence to Mr. D. G. Young, FRCS, Department of Paediatric Surgery, Royal Hospital for Sick Children, Yorkhill, Glasgow G3 8SJ. 